\title{
Performance evaluation of air quality dispersion models at urban intersection of an Indian city: a case study of Delhi city
}

\author{
M. Khare ${ }^{1}$, S. Nagendra ${ }^{2} \&$ S. Gulia ${ }^{1}$ \\ ${ }^{I}$ Department of Civil Engineering, \\ Indian Institute of Technology Delhi, New Delhi, India \\ ${ }^{2}$ Department of Civil Engineering, \\ Indian Institute of Technology Madras, Chennai, India
}

\begin{abstract}
Air quality modelling plays an important role in formulating air pollution control and management strategies by providing guidelines for better and more efficient air quality planning. Several air quality dispersion models are used to evaluate the urban air quality. The performance and efficiency of an air quality model are mainly depends upon the accurately interpretations of the complex interactions between various atmospheric, emission and topographic parameters involved in the air pollution problem. In this paper, four state-of art air quality models like AERMOD, ADMS- Urban, ISCST3 and CALINE4 and two codes i.e. GFLSM and DFLSM (based on Gaussian principle) have been used to predict the air quality of an urban intersection of Delhi city, India, followed by their performance evaluation. These models are applied to predict the concentration of Carbon monoxide $(\mathrm{CO})$, Nitrogen dioxide $\left(\mathrm{NO}_{2}\right)$ and $\mathrm{PM}_{2.5}$ (size less than 2.5 micron) which are one of the major components of vehicular exhaust emissions. The performance of all models/codes have been evaluated using standard statistical descriptor like Index of Agreement (d), Factor of 2 (FAC2), Fractional Bias (FB), Normalized Mean Square Error (NMSE), Geometric Mean Bias and Geometric Mean Variance.

The index of agreement (d) value for CO concentration indicates that ISCST3 model $(\mathrm{d}=0.69)$ performs satisfactorily when compared with AERMOD $(\mathrm{d}=0.50)$ and ADMS-Urban $(\mathrm{d}=0.45)$ for winter period. The performances of CALINE 4, DFLSM and GFLSM have been observed not satisfactory having d values less than 0.4. Further, the ADMS - urban has performed satisfactorily in predicting
\end{abstract}


$\mathrm{NO}_{2}$ concentration when compared with ISCST3 and AERMOD having $\mathrm{d}$ value as 0.49. In case of $\mathrm{PM}_{2.5}$, the AERMOD, ISCST3 and ADMS- urban have performed satisfactorily having d values as $0.46,0.45$ and 0.43 respectively. Keywords: air quality models, Vehicular pollution, AERMOD, ADMS-urban, ISCST3, CALINE4, GFLSM, DFLSM, statistical descriptors and model evaluation.

\section{Introduction}

Vehicular pollution is one of the most serious and rapidly growing environmental problems in the large cities of the developing world. The rapidly growing vehicle fleets, distance travelled by each vehicle, and change in land use pattern are some of the primary causes of vehicular air pollution, which is responsible for increase in asthma and other respiratory diseases among urban population [1]. Vehicles in major metropolitan cities of India are estimated to account for $70 \%$ of CO, $50 \%$ of HC, $30-40 \%$ of NOx, $30 \%$ of SPM and $10 \%$ of $\mathrm{SO}_{2}$ of the total load of these cities, of which two-third is contributed by two wheelers alone [2]. This rapid growth of motor vehicles ownership and activities in Indian cities are causing a wide range of serious health, environmental and socio-economic impacts [3]. The total motor vehicles population in India has also increased from 0.3 million in 1951 to 115 million in year 2009 of which, two wheelers account for $70 \%$ of the total vehicular population [4]. Accurate prediction and assessment of vehicular pollution level is important step towards management of vehicular pollution level. Line source dispersion models represent essential computational tools for predicting the air quality impacts of emissions from road traffic and are widely used in urban and municipal planning. They are extensively used throughout the world including India to carry out the prediction of vehicular pollutant concentrations along highway road in both urban as well rural areas. Various line source dispersion models are used to predict the pollutants concentration [5]. These are HIGHWAY model [6] which further evaluated in to HIGHWAY-2 [7], General Motor, GM [8], CALINE series model which was further evaluated in to CALINE 3 [9] followed by CALINE 4 [10], latest in CALINE series. Majumdar et al. [11] reveals that CALINE 4 with correction factors $(0.37)$ can be applied reasonably well for the prediction of $\mathrm{CO}$ in the city of Kolkata. Bhanarkar et al. [12] assessed the $\mathrm{SO}_{2}$ and $\mathrm{NO}_{2}$ pollution level in Jamshedpur region by ISCST3 model and observed that predicted 24-h concentrations have good agreement with measured concentrations at 11 ambient air monitoring stations. Ganguly et al., [13] had used two models CALINE 4 and GFLSM [14] and done comparative evaluation. Further, the commercial available air quality models e.g. AERMOD [15] and ADMS-Urban [16] are highly advanced and complex but user-friendly. Kumar, et al. [17] observed that AERMOD has a tendency to under-predict both under stable and unstable conditions when the model was applied for Ohio, USA. Long et al. [19] studied that sensitivity of AERMOD to input parameters and found out that AERMOD is very sensitive to surface roughness than other input parameters like solar radiation, cloud cover and albedo. Over 70 U.K. local 
authorities have extensively used the ADMS Urban for control of air pollution at designated air quality control regions (AQCRs). Mohan et al. [20] found out that AERMOD has a greater tendency to over-predict when compared to ADMS-Urban. This difference is due to difference in treatment of atmospheric stability. Also, use of sophisticated parameterization does not always yield good results as in this case. Both performed better for monthly averages than 24 hourly averages. The performance and accuracy of the air quality models is mainly depends upon accuracy input parameters. The CALINE 4 model require vehicles number and single weighted emission factor $(\mathrm{g} / \mathrm{mile})$, which represent all types of vehicles, while ISCST3, AERMOD and ADMS-Urban models needs hourly emission rates $(\mathrm{g} / \mathrm{s})$. ISCST3 and CALINE 4 model is required stability class while AERMOD and ADMS-Urban worked on monin abukhov length. AERMOD required upper air sounding data. In this study, four state-of art air quality models like AERMOD, ADMS- Urban, ISCST3 and CALINE4 and two codes i.e. GFLSM and DFLSM [21] have been setup and run to predict air quality of the Income Tax Office (ITO), intersection in Delhi city, India, followed by their performance evaluation.

\section{Methodology}

\subsection{Site characteristics}

The Income Tax Office (ITO) is one of the busiest intersections in Delhi. It is located at $28^{\circ} 37^{\prime} 39.70^{\prime \prime} \mathrm{N}$ and $77^{\circ} 14^{\prime} 28.60^{\prime \prime} \mathrm{E}$. The four major roads meet at this intersection (figure 1). The ITO intersection is surrounded by a commercial and residential area. The main commercial offices near the ITO intersection is the University Grant Commission office (in North West), Delhi Police Headquarters, Income Tax office, Delhi Secretariat office (all three are in the East direction) and Connaught Place located in the south direction. The largest residential area near the intersection is the IP estate. The pollution monitoring site governed by CPCB is located $12 \mathrm{~m}$ from BSZ Marg outside the premises of the Indian National Science Academy (INSA) (Figure 1).

Mohan and Kandya [22] has calculated AQI for Delhi city based on 9 years' pollution monitoring data at seven different locations and found that air quality at the ITO intersection is worst in the city amongst all the monitoring stations which may be due to high traffic density and congestion at the ITO intersection. The annual average concentration of $\mathrm{CO}$ and $\mathrm{PM}_{2.5}$ at BSZ marg was $2469 \mu \mathrm{g} / \mathrm{m}^{3}$ and 102 during 2007, while monthly average concentration of $\mathrm{CO}$ and $\mathrm{PM}_{2.5}$ varied from $1688 \mu \mathrm{g} / \mathrm{m}^{3}$ to $4531 \mu \mathrm{g} / \mathrm{m}^{3}$ and $34 \mu \mathrm{g} / \mathrm{m}^{3}$ to $198 \mu \mathrm{g} / \mathrm{m}^{3}$. High levels of $\mathrm{CO}$ and $\mathrm{PM}_{2.5}$ concentration might be attributed to an increase in vehicular population in Delhi [23]. Goyal et al. [24] reported that $17 \%$ and $28 \%$ of total NOx and PM concentration respectively are due to vehicular pollution, which is almost the same as those from other sources such as industry, power plants, and domestic uses in Delhi. 


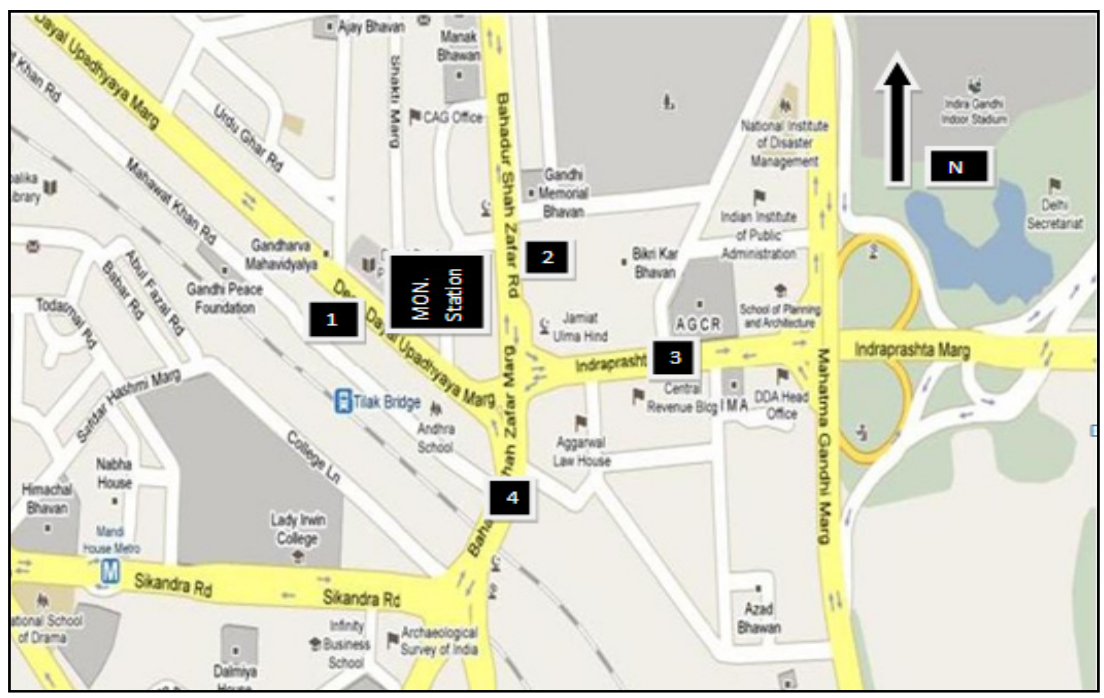

Figure 1: $\quad$ Site view of the ITO intersection, Delhi.

\subsection{Traffic characteristic}

The traffic data at the ITO intersection has been collected from Central Road Research Institute (CRRI), New Delhi. The traffic volume on Roads 3 and 4 have been observed to be greater than the other two roads (Roads 1 and 2).

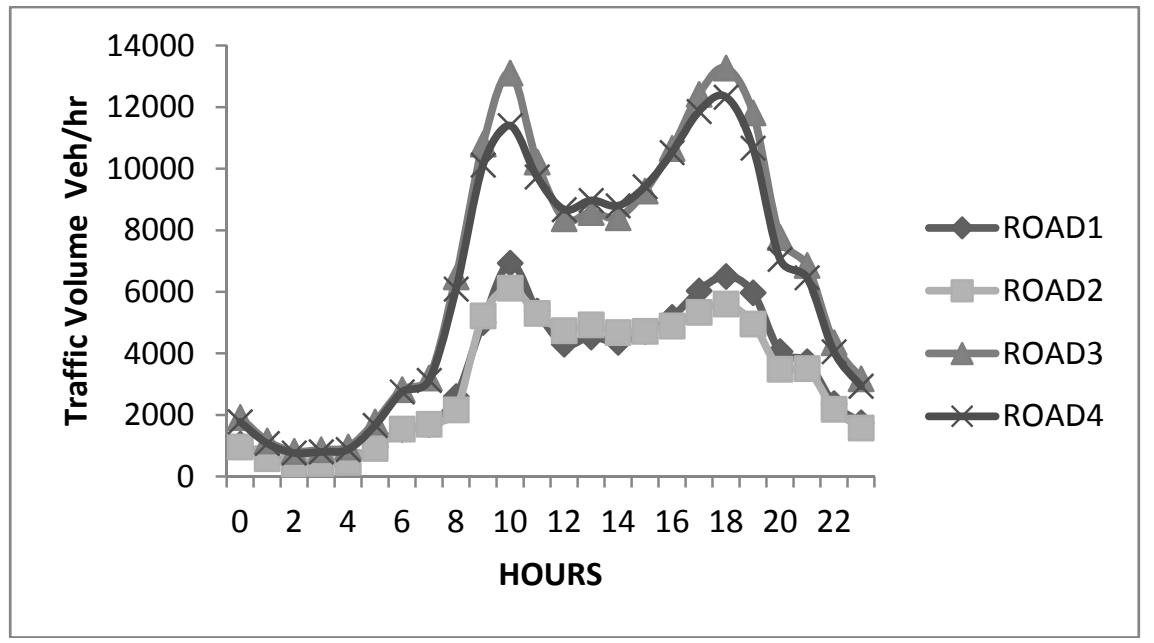

Figure 2: Diurnal traffic pattern at the ITO intersection.

The maximum traffic has been observed between 8:00 and 10:00am (morning peak hour) and between 5:00 and 7:00pm (evening peak hours) (Figure 2). The 
traffic fleet of Delhi is composed of 2-wheeler (2-stroke and 4-stroke), 3-wheeler (CNG driven), cars/ jeep (petrol, diesel and Compressed Natural Gas, CNG driven), light commercial vehicle (LCV), buses (CNG and diesel driven) and heavy commercial vehicle (HCV). The traffic fleet of ITO intersection is shown below in figure 3.

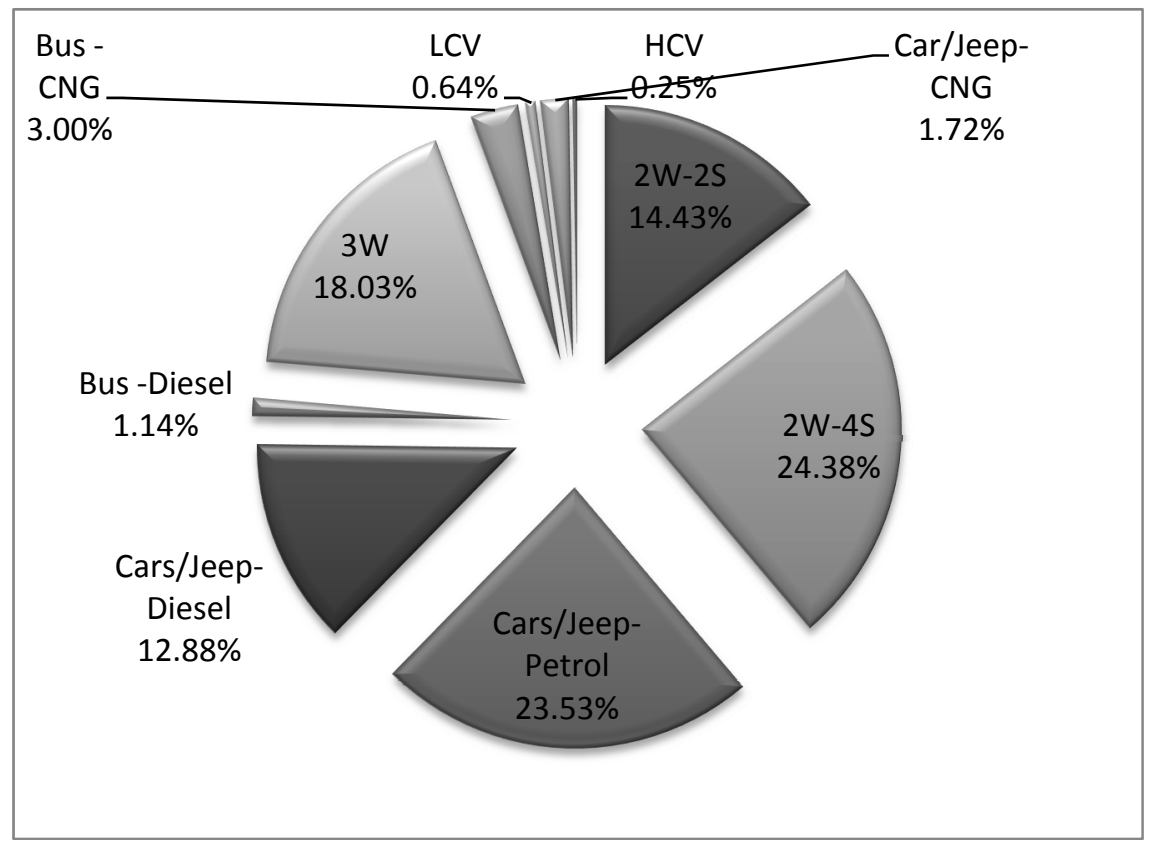

Figure 3: Traffic fleet characteristic of the ITO intersection.

The portion of 2 -wheeler $(2 \mathrm{~W})$ is highest i.e. $38.8 \%(2 \mathrm{~W}-2$-Stroke $=14.4 \%$ and $2 \mathrm{~W}-4$ stroke $=24.4 \%$ ) followed by cars $36.3 \%$ (petrol driven $=23.5 \%$ and diesel driven $=12.8 \%$ ). In total traffic composition, the 3 -wheeler ( $\mathrm{CNG}$ driven) is $18.0 \%$ and bus is $4.1 \%$ (CNG driven $=3 \%$ and diesel driven $=1.1 \%$ ).

\subsection{Emission factor}

Hourly emission rates have been calculated as function of emission factor and vehicular activity data for each road link [24]. AERMOD, ADMS-Urban and ISCST3 does not take these emission rates directly, instead it takes the hourly factors that can be multiplied to a common emission rate for that link so as to get the original emission rates. The weighted emission factor has been calculated for CALINE 4 model based on emission factors and traffic volume for each road link. 


\subsection{Meteorological data}

The meteorological data collected from Indian meteorological department, Delhi for winter and summer periods. The analysis shows that the winter and summer periods have $43 \%$ and $53 \%$ of calm condition respectively (Figure 4(a) (b).

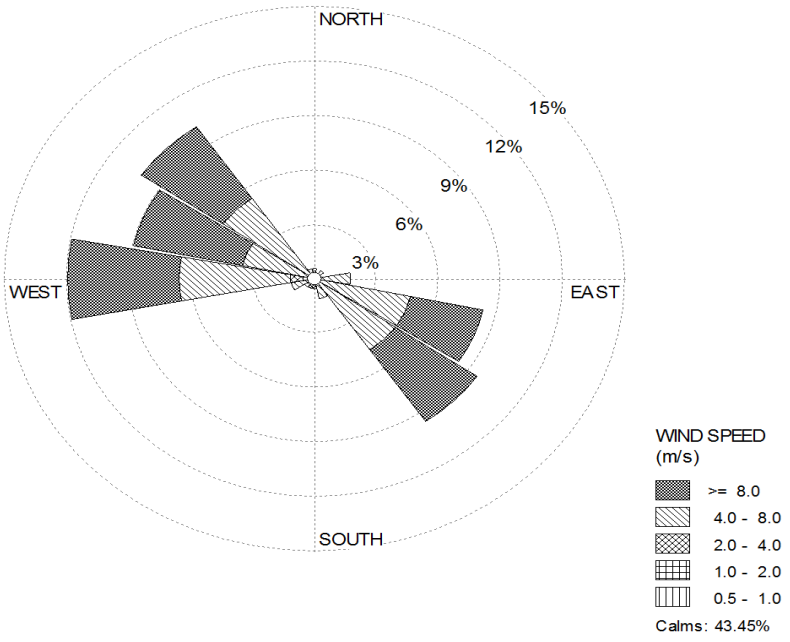

(a)

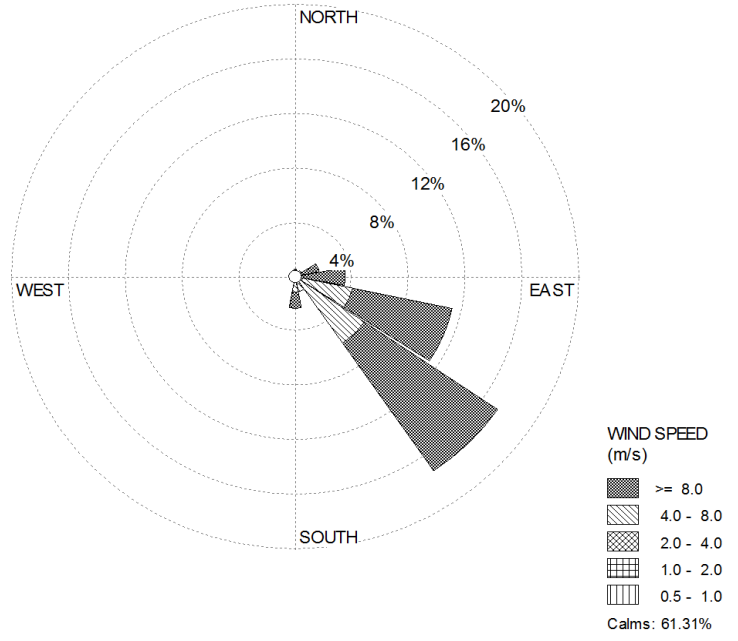

(b)

Figure 4: $\quad$ Windrose diagram for (a) January 2007 and (b) May 2007. 
In winter, the winds are mostly westerly, north westerly and south easterly having frequent fluctuations. In summer, winds are mostly south easterly having frequent fluctuations. The upper air meteorological data required for AERMOD has been collected from (www.weather.uwyo.edu).

\subsection{Air quality trends}

The diurnal pattern of $\mathrm{CO}, \mathrm{NO}_{2}$ and $\mathrm{PM}_{2.5}$ monitored concentrations collected from CPCB monitoring station during one week monitoring in January and May 2007 are shown in figures 5(a) and (b) respectively.

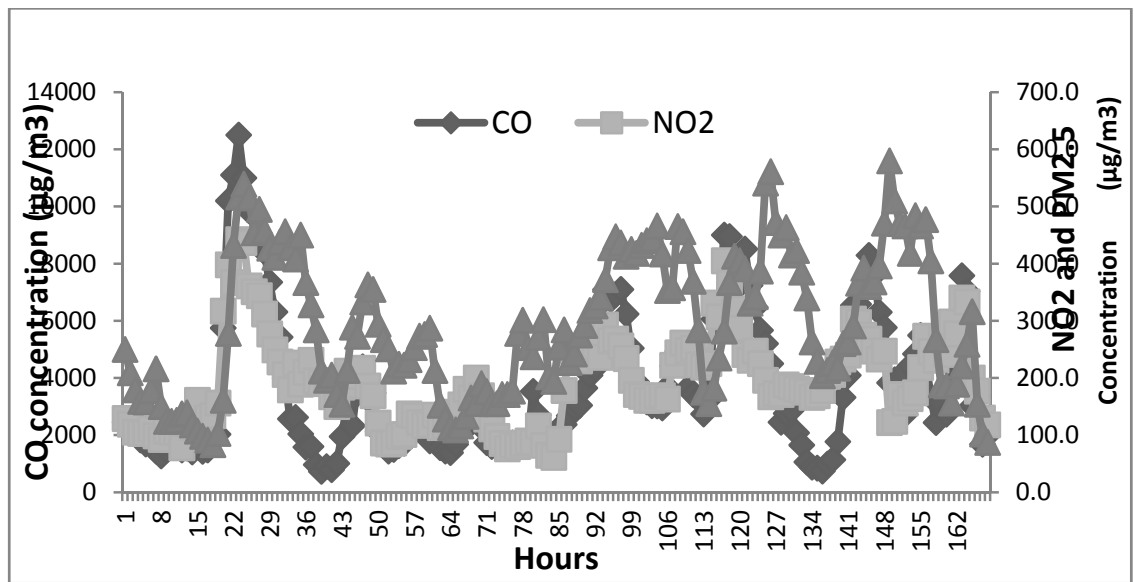

(a)

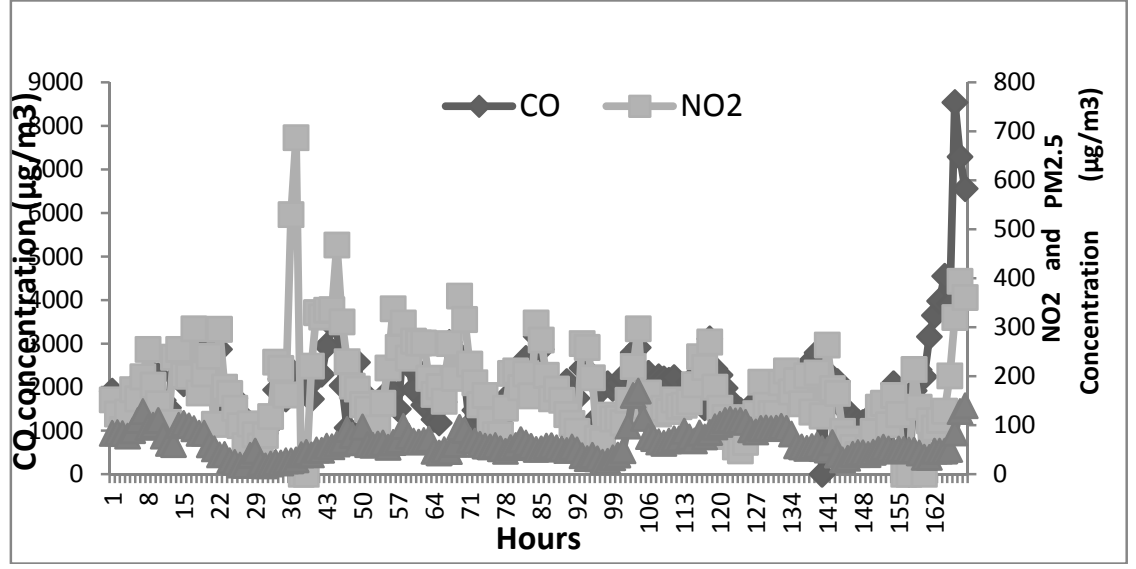

(b)

Figure 5: Weekly variations of monitored $\mathrm{CO}, \mathrm{NO}_{2}$ and $\mathrm{PM}$ concentration for (a) January 2007 and (b) May 2007. 
The background concentrations for CO for the months of January and May have been $1400 \mu \mathrm{g} / \mathrm{m}^{3}$ and $1250 \mu \mathrm{g} / \mathrm{m}^{3}$, respectively. The background concentrations for $\mathrm{NO}_{2}$ and $\mathrm{PM}_{2.5}$ have been taken corresponding to the lowest point on the curve of monitored data [25]. The background concentration of $\mathrm{NO}_{2}$ for winter and summer period has been taken $61 \mu \mathrm{g} / \mathrm{m}^{3}$ and $40 \mu \mathrm{g} / \mathrm{m}^{3}$ respectively. The background concentration of $\mathrm{PM}_{2.5}$ for winter and summer period has been taken $83 \mu \mathrm{g} / \mathrm{m}^{3}$ and $25 \mu \mathrm{g} / \mathrm{m}^{3}$ respectively.

\section{Setting up of models}

All the four models and two codes have been setup for prediction of $\mathrm{CO}$ concentration for winter period using traffic, meteorology and emission data. Further AERMOD, ADMS-Urban and ISCST3 model have been setup for summer period to predict the $\mathrm{CO}, \mathrm{NO}_{2}$ and $\mathrm{PM}_{2.5}$ concentrations. The whole intersection has been divided in 10 road links based on traffic count, road terrain and alignment, which are used in AERMOD, ADMS-Urban and CALINE4 model. For DFLSM and GFLSM codes, the intersection is divided in two roads.

\section{Results and discussions}

Statistical descriptors mainly index of agreement ' $\mathrm{d}$ ', factor of 2 (FAC2), fractional bias (FB) and normal mean square error (NMSE) are used to evaluate the model performance. According to Kumar et al., [17] the performance of the model can be deemed acceptable if: $0.4 \leq \mathrm{d} \leq 1.0,-0.5 \leq \mathrm{NMSE} \leq 0.5,0.5 \leq \mathrm{FB}$ $\leq 0.5$ and FAC $2 \geq 0.8$. Tables 1 to 3 show the model performance results.

Table 1: $\quad$ Statistical performance of models for $\mathrm{CO}$ prediction.

\begin{tabular}{|c|c|c|c|c|c|c|c|c|}
\hline \multirow{2}{*}{ Models } & \multicolumn{2}{|c|}{$\begin{array}{c}\text { Index of } \\
\text { Agreement }\end{array}$} & \multicolumn{2}{|c|}{ FAC2 } & \multicolumn{2}{c|}{ FB } & \multicolumn{2}{c|}{ NMSE } \\
\cline { 2 - 9 } & Jan & May & Jan & May & Jan & May & Jan & May \\
\hline AERMOD & 0.50 & 0.51 & 0.86 & 0.95 & 0.27 & 0.14 & 0.24 & 0.24 \\
\hline ISCST3 & 0.69 & 0.59 & 0.98 & 0.89 & 0.19 & 0.18 & 0.18 & 0.18 \\
\hline ADMS & 0.45 & 0.44 & 0.85 & 0.92 & 0.74 & 0.15 & 0.27 & 0.28 \\
\hline CALINE 4 & 0.37 & & 1.01 & & 0.26 & & 0.02 & \\
\hline GFLSM & 0.34 & & 1.16 & & 0.15 & & 0.53 & \\
\hline DFLSM & 0.4 & & 1 & & 0.24 & & 0.42 & \\
\hline
\end{tabular}

The index of agreement $(d)$ value for $\mathrm{CO}$ concentration $(\mathrm{d}=0.689)$ indicates that ISCST3 model performs satisfactory for $\mathrm{CO}$ prediction when compared to AERMOD $(\mathrm{d}=0.5)$, ADMS-Urban $(\mathrm{d}=0.45)$, CALINE 4( $\mathrm{d}=0.37)$, GFLSM $(\mathrm{d}=0.34)$ and DFLSM $(\mathrm{d}=0.40)$ (Table 1). The ADMS-Urban performs satisfactorily for predicting $\mathrm{NO}_{2}$ concentration $(\mathrm{d}=0.48)$ when compared to 
AERMOD ( $d=0.32)$ and ISCST3 $(\mathrm{d}=0.36)$ (Table 2). The $\mathrm{d}$ value for $\mathrm{PM}_{2.5}$ as predicted by AERMOD, ISCST3 and ADMS-Urban are 0.46, 0.45 and 0.43 , respectively (Table 3 ). This shows that all three models are performing satisfactorily. Fractional bias gives the estimates of extremities in under prediction or over prediction. The $\mathrm{FB}$ values for $\mathrm{CO}$ and $\mathrm{PM}_{2.5}$ concentrations are positive that show that models under-predict. The $\mathrm{FB}$ values for $\mathrm{NO}_{2}$ for AERMOD and ISCST3 are negative; it shows that models over- predict. NMSE value of all models is below 0.5 (except GFLSM for CO and ADMS-urban for $\mathrm{PM}_{2.5}$ ). It shows satisfactory performance of all models.

Table 2: $\quad$ Statistical performance of AERMOD, ISCST3 and ADMS-Urban for $\mathrm{NO}_{2}$ prediction.

\begin{tabular}{|c|c|c|c|c|c|c|c|c|}
\hline \multirow{2}{*}{ Models } & \multicolumn{2}{|c|}{$\begin{array}{c}\text { Index of } \\
\text { Agreement }\end{array}$} & \multicolumn{2}{|c|}{ FAC2 } & \multicolumn{2}{c|}{ FB } & \multicolumn{2}{c|}{ NMSE } \\
\cline { 2 - 9 } & Jan & May & Jan & May & Jan & May & Jan & May \\
\hline AERMOD & 0.32 & 0.35 & 1.78 & 1.15 & -0.53 & -0.12 & 0.2 & 0.14 \\
\hline ISCST3 & 0.36 & 0.4 & 1.43 & 0.97 & -0.34 & 0.02 & 0.15 & 0.12 \\
\hline ADMS & 0.48 & 0.45 & 0.61 & 0.7 & 0.66 & 0.67 & 0.21 & 0.18 \\
\hline
\end{tabular}

Table 3: $\quad$ Statistical performance of AERMOD, ISCST3 and ADMS-Urban for PM2.5 prediction.

\begin{tabular}{|c|c|c|c|c|c|c|c|c|}
\hline \multirow{2}{*}{ Models } & \multicolumn{2}{|c|}{$\begin{array}{c}\text { Index of } \\
\text { Agreement }\end{array}$} & \multicolumn{2}{c|}{ FAC2 } & \multicolumn{2}{c|}{ FB } & \multicolumn{2}{c|}{ NMSE } \\
\cline { 2 - 10 } & Jan & May & Jan & May & Jan & May & Jan & May \\
\hline AERMOD & 0.46 & 0.42 & 0.44 & 0.64 & 0.9 & 0.61 & 0.5 & 0.4 \\
\hline ISCST3 & 0.45 & 0.44 & 0.43 & 0.61 & 0.93 & 0.64 & 0.49 & 0.42 \\
\hline ADMS & 0.43 & 0.42 & 0.41 & 0.65 & 1.08 & 0.61 & 0.52 & 0.48 \\
\hline
\end{tabular}

\section{Conclusions}

The AERMOD, ADMS-Urban and ISCST3 perform satisfactory when compared to CALINE4, DFLSM and GFLSM for predicting CO concentrations. The ISCST3 performs satisfactorily when compared to AERMOD and ADMSUrban. The accuracy in the upper meteorological data characterizing the vertical profiles and taking into account the actual variations in turbulence and temperature throughout the mixing layer depth may be one of the significant reasons resulting into the under-prediction by AERMOD when compared to ISCST3. The ' $d$ ' values indicate that ADMS-Urban $(d=0.48)$ perform satisfactorily for predicting $\mathrm{NO}_{2}$ concentrations when compared to AERMOD $(d=0.32)$ and ISCST3 $(d=0.36)$. The ' $d$ ' values for $\mathrm{PM}_{2.5}$ concentrations for AERMOD, ISCST3 and ADMS-Urban have been $0.46,0.45$ and 0.43 , 
respectively. It shows that all three models are performing satisfactorily. The FB values are positive for all the models (except AERMOD and ISCST3 for $\mathrm{NO}_{2}$ prediction). It describes that these models are under-predicting, while AERMOD and ISCST3 are over predicting for $\mathrm{NO}_{2}$ concentrations.

\section{Acknowledgements}

The research work is a part of the ongoing UKIERI funded research project entitled "Evaluation of Quantitative Dispersion Models for Urban Air Quality Assessment". We wish to thank the UKIERI, New Delhi. The author would like to thanks HSBC (INDIA) for sponsoring the HSBC-UKIERI Senior Research Fellow position to work on this research project. We also acknowledge with thanks the CERC, UK who has provided us the ADMS - urban for academic and research purposes at a very competitive price.

\section{References}

[1] Mayer, H., Air pollution in cities. Atmospheric Environment (33), pp. 40294037, 1999.

[2] Sharma, N., Chaudhry, K.K. and Rao, C.V.C., Vehicular pollution modelling in India. Journal of the Institution of Engineers (India), (85), pp. 46-63, 2005.

[3] Badami, M. G., Urban transport policy as if people and the environment mattered: Pedestrian accessibility the first step. Economic \& Political Weekly, EPW Vol. XLIV (33), 2009.

[4] CPCB, Status of vehicular pollution control program in India, Program Objective Series/PROBES/136/2010.

[5] Nagendra, S.M.S. and Khare, M., Line source emission modelling- review. Atmospheric Environment, 36 (13), pp. 2083-2098, 2002.

[6] Zimmerman, J.P., Thompson, R.S., User's guide for HIWAY, A highway air pollution model, EPA-650/4-74-008, 1975.

[7] Peterson, W.B., User's guide for HIWAY-2, Highway air pollution model, EPA-600/8-80-018, 1980.

[8] Chock, D.P., A simple line-source model for dispersion near roadways. Atmospheric Environment, (12), 823 $\pm 82,1978$.

[9] Benson, P.E., CALINE-3, A versatile dispersion model for predicting air pollution levels near highways and arterial streets FHWA/CA/TL-79/23, California Department of Transportation, Sacramento, CA. 1979.

[10] Benson, P.E., CALINE-4: A dispersion model for predicting air pollutant concentrations near roadways. Final Report, FHWA/ CA/TL-84-15, California Department of Transportation, Sacramento, CA. 1984.

[11] Majumdar, B. K., Dutta, A., Chakrabarty, S., and Ray, S., Correction factors of CALINE 4: A study of automobile pollution in Kolkata, Indian Journal of Air Pollution Control, 8 (1), pp. 1-7, 2008.

[12] Bhanarkar, A.D., Goyal, S. K., Sivacoumar, R., and Rao C.V.C., Assessment of contribution of $\mathrm{SO}_{2}$ and $\mathrm{NO}_{2}$ from different sources in 
Jamshedpur region, India. Atmospheric Environment, (39), pp. 7745-7760, 2005.

[13] Ganguly, R., Broderick, B. M. and O'Donoghue, R., Assessment of a general finite line source model and CALINE 4 for vehicular pollution prediction in Ireland, Environ Model Assess, (14), pp. 13-125, 2009.

[14] Luhar, A.K. and Patil, R.S., A general finite line source model for vehicular pollution prediction. Atmospheric Environment, 23 (3), pp. 555-562, 1989.

[15] U.S. Environment Protection Agency, Federal Register, Part -III, 40 CFR Part 51, Revisions to the guideline on air quality models: Adoption of a Preferred General Purpose (Flat and Complex Terrain) Dispersion Model and Other Revisions; Final Rule. 2005.

[16] Carruthers, D.J., Blair, J.W. and Johnson, K.L., Validation and sensitivity study of the ADMS-Urban, TR - 0191, 2003.

[17] Kumar, A., Dixit, S., Varadarajan, C., Vijayan, A. and Masuraha, A., Evaluation of the AERMOD dispersion model as a function of atmospheric stability for an urban area. Environmental Progress, 25(2), 2006.

[18] Cambridge Environmental Research Consultants, ADMS -Urban model user guide, 2006.

[19] Long, E.L., Cordova, F.J., \& Tanrikulu, S., An analysis of AERMOD sensitivity to input parameters in the San Francisco Bay Area, 13th Conference on the Applications of Air Pollution Meteorology with the Air and Waste Management Association, American Meteorological Society, Vancouver, BC, August, 23-25, 2004.

[20] Mohan, M., Bhati, S. and Marrapu, P., Performance evaluation of AERMOD and ADMS -Urban models in a tropical urban environment. Indian Journal of Air pollution Control, 9(1), pp 47-62, 2009.

[21] Khare, M. and Sharma, P., Performance evaluation general finite line source model for Delhi traffic conditions. Transportation Research: PartD, (4), pp. 65-70, 1999.

[22] Mohan, M. and Kandya, A., An analysis of annual and seasonal trends of air quality index of Delhi, Environmental Monitoring and Assessment, (131), pp. 267-277, 2007.

[23] Central Pollution Control Board, National ambient air quality status report, 2007, (www.cpcb.nic.in).

[24] Goyal, P., Jaiswal, N., Kumar, A., Dadoo, J.K. and Dwarakanath M., Air quality impact assessment of NOx and PM due to diesel vehicles in Delhi. Transportation Research Part D, (15), 298-303, 2010.

[25] ARAI, Emission factor development for Indian vehicles. Project Report No.AEF/2006-07/IOCL/Emission Factor Project. Automotive Research Association of India, Pune, 2007.

[26] Aneja, V. P., Agrawal, A., Roelle, P. A., Philips, S. B., Tong, Q., Watkins, N., 2001. Measurement and analysis of criteria pollutants in New Delhi, India. Environmental Modelling \& Software, 27(1), pp. 35-42, 2001. 